\title{
Life-threatening retroperitoneal hematoma after percutaneous vertebroplasty for lumbar fracture
}

\author{
Catarina Aleixo $^{1 *}$, Jose Marinhas ${ }^{1}$, Filipe Santos ${ }^{1}$, Rolando Freitas $^{2}$, Ricardo Santos Pereira ${ }^{1}$
}

${ }^{1}$ Department of Orthopaedics, Centro Hospitalar Vila Nova de Gaia, Espinho, Vila Nova de Gaia, Portugal

${ }^{2}$ Department of Orthopaedics, Unidade Local de Saude do Alto Minho, Viana do Castelo, Portugal

Received: 15 April 2020

Accepted: 08 May 2020

*Correspondence:

Dr. Catarina Aleixo,

E-mail: catarinabpaleixo@gmail.com

Copyright: () the author(s), publisher and licensee Medip Academy. This is an open-access article distributed under the terms of the Creative Commons Attribution Non-Commercial License, which permits unrestricted non-commercial use, distribution, and reproduction in any medium, provided the original work is properly cited.

\begin{abstract}
Percutaneous vertebroplasty is a safe and effective minimally invasive procedure with specific potential complications. Among these, vascular injuries have seldomly been reported. We present a rare case of retroperitoneal hematoma, presumably from injury to one of the lumbar arteries following percutaneous vertebroplasty in a patient treated for lumbar fracture. Even though the situation was life-threatening, conservative treatment and support measures sufficed in controlling the bleeding and the patient recovered fully. Spine surgeons should be especially aware of this specific and often late-presenting complication, as early recognition and prompt treatment are fundamental to decrease its morbidity and mortality.
\end{abstract}

Keywords: Hematoma, Vertebroplasty, Lumbar fracture

\section{INTRODUCTION}

Percutaneous vertebroplasty is a safe and effective minimally invasive procedure used to treat symptomatic osteoporotic vertebral compression fractures (VCF), and it is usually performed using a transpedicular approach.

Complications from percutaneous vertebral augmentation procedures such as vertebroplasty and kyphoplasty are infrequent and are most commonly related to cement leakage. ${ }^{1}$

The most frequently reported are pulmonary emboli and neurologic deficits. ${ }^{2}$ Vascular arterial complications related to percutaneous vertebral augmentation procedures have been rarely reported, and only in isolated case reports. ${ }^{3}$

Here, we present a rare case of life-threatening retroperitoneal hematoma following percutaneous vertebroplasty using the transpedicular approach.

\section{CASE REPORT}

A 77 years old female patient with no significant past medical history was observed at our hospital's emergency department with complaints of lower back pain (visual analogue scale - VAS 8) with no neurologic impairment after sustaining a simple fall two days earlier. She was diagnosed with a stable vertebral body fracture of the first lumbar vertebra - AO type A1 (Figure 1 and 2) and was discharged home with oral analgesics and a Jewett-type orthosis.

The patient was reevaluated one month later at our outpatient clinic and complained of persistent incapacitating lower back pain that severely affected her daily activities, and showed a mild collapse of the vertebral body on the radiograph (Figure 3). As conservative treatment was unsuccessful, a vertebroplasty was proposed. The patient consented and the procedure was performed a few days later. Under fluoroscopic control, a unilateral percutaneous right transpedicular approach was 
utilized for the injection of polymethylmethacrylate (PMMA) bone cement. The operative procedure was seamlessly uneventful and the follow-up radiographs showed only minor extravasation of cement into the right paravertebral soft tissues (Figure 4).

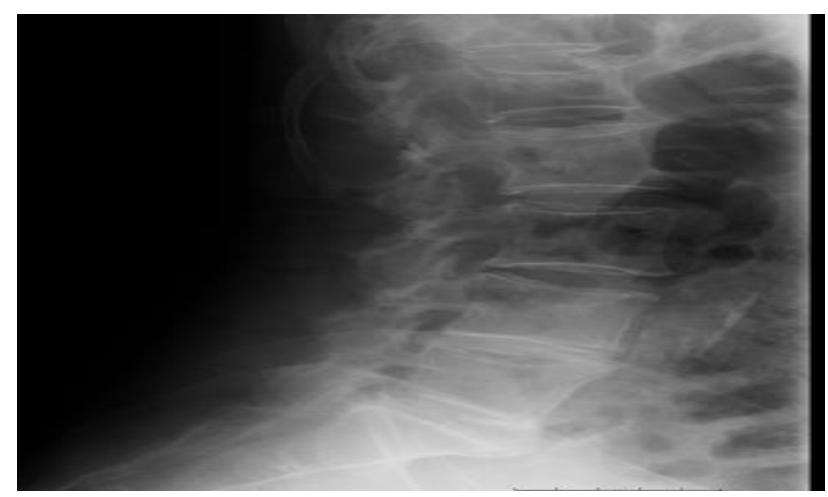

Figure 1: Initial radiograph at hospital's emergency department.

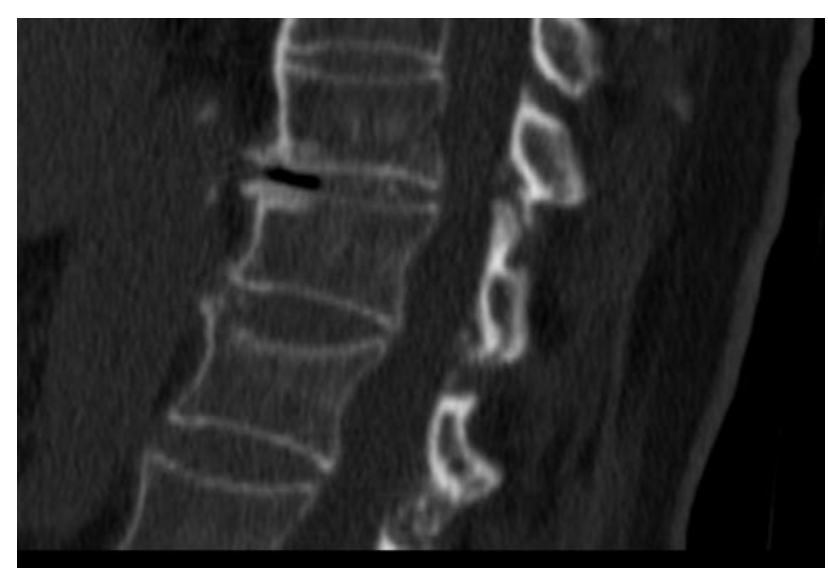

Figure 2: CT scan of first lumbar body fracture.

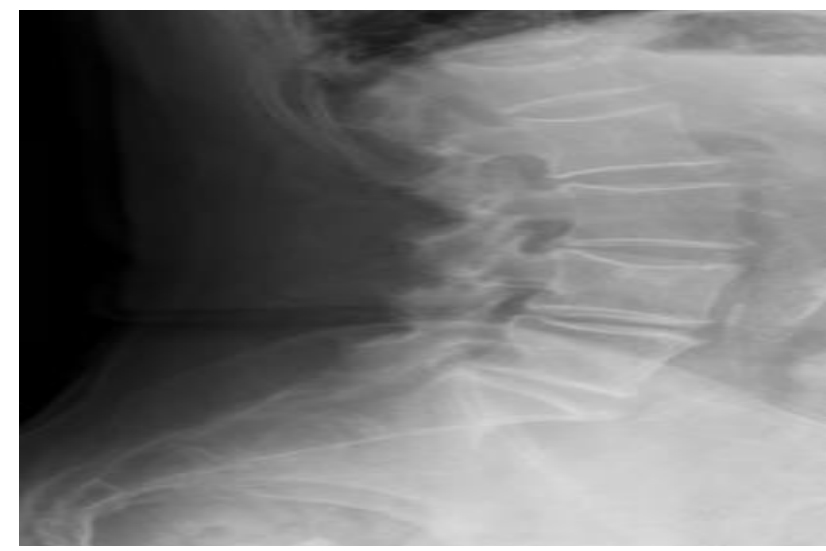

Figure 3: Radiograph showing mild collapse of the vertebral body (1 month).

In the first post-operative day the pain had subsided and the patient was discharged from the hospital. On the $7^{\text {th }}$ post-operative day, the patient was readmitted to the hospital with complains of severe progressive lower back pain with irradiation to the right flank and groin. Laboratory tests showed a decrease in hemoglobin levels (from 13.4 to $10.9 \mathrm{~g} / \mathrm{dl}$ ) and increased inflammatory markers. Platelet count and coagulation parameters were normal. An abdominal ultrasound showed a hypoecogenic, heterogeneous fusiform mass in the right extra-peritoneal space, with $16 \mathrm{~cm}$ of longitudinal diameter and $5 \mathrm{~cm}$ of width, consistent with a possible organized hematoma. Further characterization was performed with an abdominal CT-angiogram confirming the presence of a voluminous retroperitoneal (posterior para-renal) hematoma with $100 \times 70 \times 50 \mathrm{~mm}$ dimensions, with no signs of active bleeding (Figure 5 and 6).

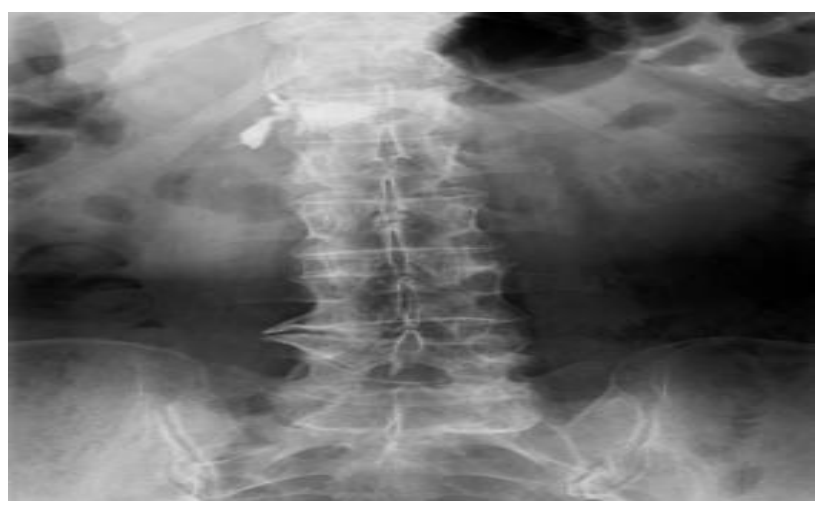

Figure 4: Post-operative radiograph showing minor extravasation of cement into the right paravertebral soft tissues.

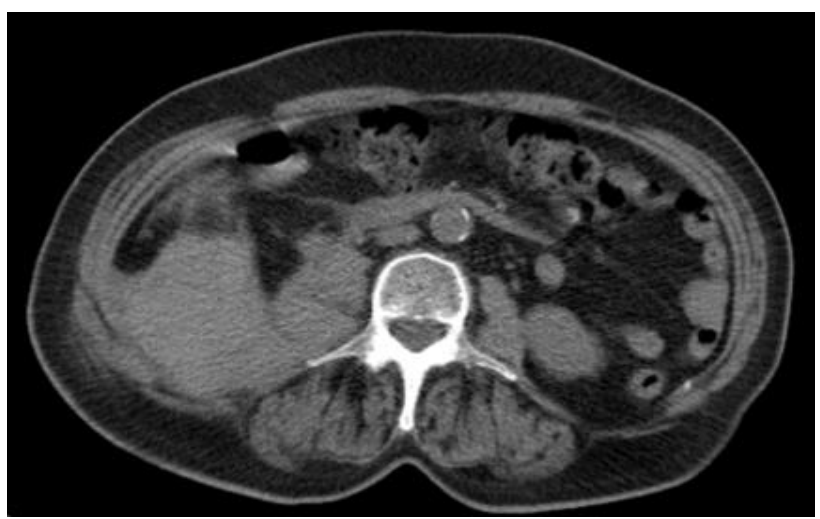

Figure 5: Abdominal CT scan showing retroperitoneal hematoma (axial view).

The patient was admitted to the hospital for pain control and hemodynamic monitoring. Her abdomen became increasingly tender, with a palpable mass in the right flank. Serum hemoglobin levels dropped from 10.9 to $8.8 \mathrm{~g} / \mathrm{dl}$ in the first two days of monitoring, with associated paleness and fatigue. At this time blood trans-fusional support was proposed to the patient but she refused it due to religious beliefs.

Three days after admission the patient started desaturating and became increasingly pale, sudoretic and tachycardic $(125 \mathrm{bpm})$. She remained conscious (Glasgow coma 
scale 15) and with blood pressure within normal limits $(135 / 72 \mathrm{mmHg})$. Her serum hemoglobin levels dropped once again to $7.4 \mathrm{~g} / \mathrm{dl}$. An urgent comparative abdominal CT-angiogram was requested - showing a moderate increase in the hematoma's dimensions to $115 \times 84 \times 82 \mathrm{~mm}$. A small focus of active bleeding was detected at this time, lateral to the right pedicle of L1, with a $7 \mathrm{~mm}$ blush in the arterial phase as well as a small right sided pleural effusion and passive subsegmental atelectasis of the homolateral lung (Figures 7-9).

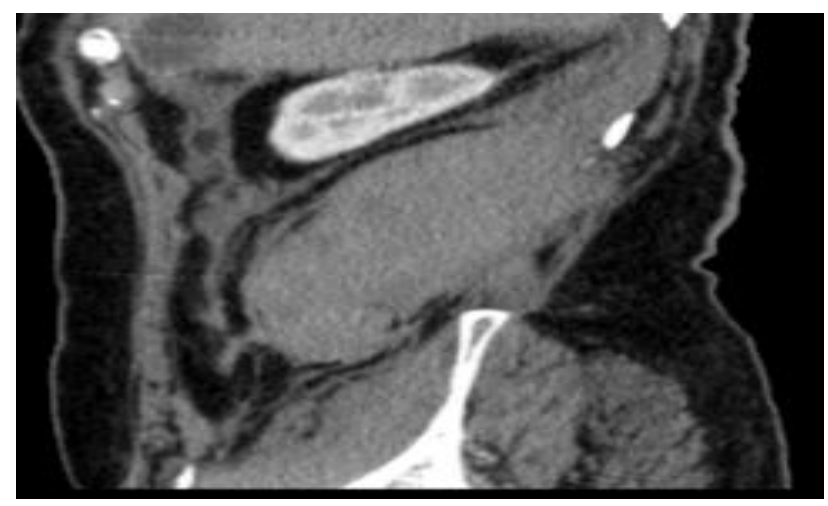

Figure 6: Abdominal CT scan showing retroperitoneal hematoma (sagital view).

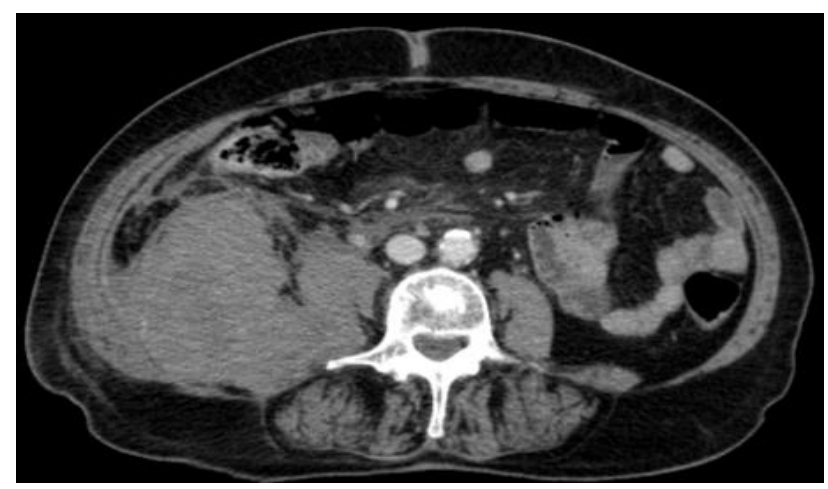

Figure 7: Follow-up abdominal CT scan showing increased dimensions of the retroperitoneal hematoma (axial view).

Vascular surgeons and intervention radiologists were consulted, but both agreed that the actively bleeding vessel was too small selective percutaneous embolization. The situation was deemed life-threatening and upon further explanation the patient finally agreed to have transfusional support. After receiving the blood transfusions, the patient became hemodynamically stable and her serum hemoglobin levels rose to $9.7 \mathrm{~g} / \mathrm{dl}$. The patient's evolution over the next days was favorable - the pain subsided and the patient maintained cardiovascular and hemoglobin stability. One week after admission a control CTangiogram showed no increase in the hematoma's dimensions and no signs of active bleeding. The patient was finally discharged home the following days.
The patient was followed in our outpatient clinic for 12 months. Despite the described initial complication, she made a full recovery, with complete resolution of the pain and return to her pre-injury status.

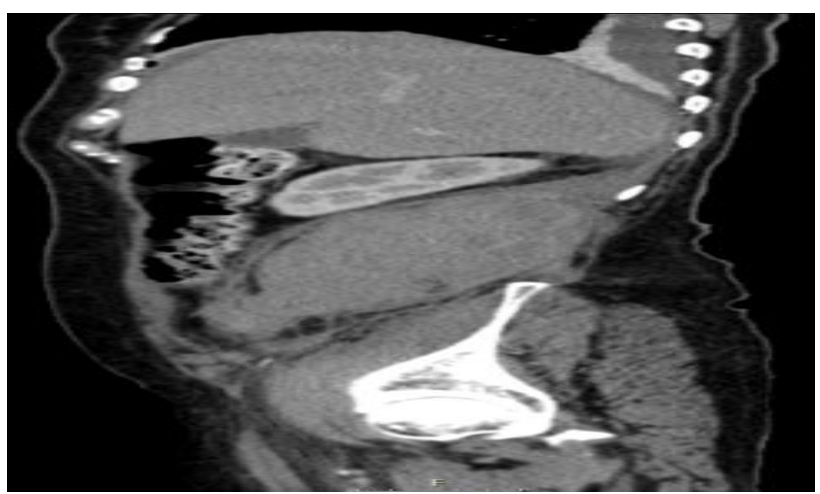

Figure 8: Follow-up abdominal CT scan showing increased dimensions of the retroperitoneal hematoma (sagital view).

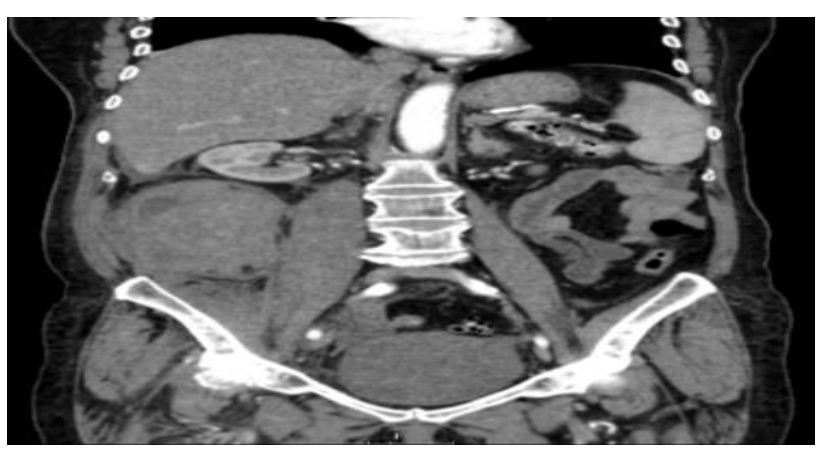

Figure 9: Follow-up abdominal CT scan showing increased dimensions of the retroperitoneal hematoma (coronal view).

\section{DISCUSSION}

Percutaneous lumbar augmentation procedures (vertebroplasty or kyphoplasty) with PMMA bone cement have emerged as widely used interventions for the treatment of pain associated with VCF, despite some controversies regarding its efficacy. ${ }^{4-6}$ Moreover, procedure-related complications, varied from $1.8 \%$ in reports to $3.8 \%$ in a meta-analysis. ${ }^{7,8}$

Frequently described complications associated with vertebral augmentation are, for the most part, minor or self-limited. They include subsequent adjacent vertebral body fractures, cement leakage, cement embolization to the lungs, rib fractures and neurologic complications. ${ }^{9}$

Although there have been case reports describing vascular complications related to vertebroplasty (such as aortic adventitial injury, infection-induced aortic aneurysm and lumbar artery injury), these potentially serious complications have not been systematically documented. ${ }^{10}$ 
We present a case of life-threatening hemorrhage following vertebroplasty, presumably from injury to one of the lumbar arteries. These arteries are small-paired vessels originating from the dorsal aspect of the abdominal aorta, at the level of the transverse processes, and run laterally along the bodies of the lumbar vertebrae. ${ }^{11}$ Each lumbar artery divides into several branches at the intervertebral foramen. ${ }^{12}$ The dorsal rami pass backwards in contact with the outer surface of the laminae, crossing each pars interarticularis. They enter the Sacro spinalis muscles, and course medially and backwards, close to the spinous process. ${ }^{9}$

The transpedicular approach is the preferred route for lumbar vertebral augmentation procedures and was the approach utilized in our case. This route is safer because the operator uses key bone landmarks to avoid the medially located spinal canal, anteriorly located aorta, and the laterally located paraspinal soft tissues, including the intersegmental arteries. ${ }^{6}$ Nevertheless, the percutaneous nature of these procedures does not allow the surgeon to visualize the arterial networks on the posterior aspect of the vertebra. ${ }^{9}$ Even with a transpedicular approach, major complications can occur if proper attention is not paid to the target anatomy visualized using high-quality biplane fluoroscopy. Lumbar arteries are in direct proximity to the midportion of the vertebral bodies. The potential for vascular injuries is therefore highly increased if the Jamshidi needle either is inserted through a parapedicular approach or breeches the lateral cortex during a transpedicular approach (as it may have happened in our case). ${ }^{6}$

As manifested by the patient presented in this article, hemorrhage from an injured lumbar artery may present with late-onset pain, anemia, and even hypovolemic shock in the most severe cases. In patients with suspected vascular injury, multiphasic contrast-enhanced CT is mandatory for the diagnosis of retroperitoneal bleeding. Whenever possible, endovascular trans-arterial embolization should be the first line of treatment to control the hemorrhage. ${ }^{3}$

Even though in our case conservative treatment and support measures sufficed in controlling the bleeding, this was still a potentially lethal complication. As such, all surgeons should be aware of its prevention, diagnosis and treatment in order to act promptly upon such cases.

\section{CONCLUSION}

Spine surgeons should be especially aware of this specific and often late-presenting complication, as early recognition and prompt treatment are fundamental to decrease its morbidity and mortality.

Funding: No funding sources

Conflict of interest: None declared

Ethical approval: Not required

\section{REFERENCES}

1. Matouk CC, Krings T, Brugge TKG, Smith R. Cement embolization of a segmental artery after percutaneous vertebroplasty: a potentially catastrophic vascular complication. Intervent Neuroradiol. 2012;18:358-62.

2. Trumm CG, Pahl A, Helmberger TK, Jakobs TF, Zech CJ, Stahl R, et al. CT fluoroscopy-guided percutaneous vertebroplasty in spinal malignancy: technical results, PMMA leakages, and complications in 202 patients. Skelet Radiol. 2012;41:1391-400.

3. Giordano AV, Arrigoni F, Bruno F, Carducci S, Varrassi M, Zugaro L, et al. Interventional Radiology Management of a Ruptured Lumbar Artery Pseudoaneurysm after Cryoablation and Vertebroplasty of a Lumbar Metastasis. Cardiovasc Intervent Radiol. 2017;40(5):776-9.

4. Buchbinder R, Osborne RH, Ebeling PR, Wark JD, Mitchell P, Wriedt C, et al. A randomized trial of vertebroplasty for painful osteoporotic vertebral fractures. N Engl J Med. 2009;361:557-68.

5. Kallmes DF, Comstock BA, Heagerty PJ, Turner JA, Wilson DJ, Diamond TH, et al. A randomized trial of vertebroplasty for osteoporotic spinal fractures. N Engl J Med. 2009;361:569-79.

6. Puri AS, Colen RR, Reddy AS, Groff MW, Nobile D, Killoran T, et al. Lumbar artery pseudoaneurysm after percutaneous vertebroplasty: a unique vascular complication. J Neurosurg Spine. 2011;14(2):296-9.

7. Layton KF, Thielen KR, Koch CA, Luetmer PH, Lane JI, Wald JT, et al. Vertebroplasty, first 1000 levels of a single center: evaluation of the outcomes and complications. AJNR Am J Neuroradiol. 2007;28:683-9.

8. Lee MJ, Dumonski M, Cahill P, Stanley T, Park D, Singh K. Percutaneous treatment of vertebral compression fractures: a meta-analysis of complications. Spine. 2009;34:1228-32.

9. Biafora SJ, Mardjetko SM, Butler JP, Carthy MPL, Gleason TF. Arterial injury following percutaneous vertebral augmentation: a case report. Spine. 2006;31(3):84-7.

10. Liu L, Cheng S, Wang Q, Liang Q, Liang Y, Jin W, et al. An anatomical study on lumbar arteries related to the extra-pedicular approach applied during lumbar PVP (PKP). PLoS One. 2019;14(3):0213164.

11. Kessel BJ, Habib FA, Thompson B, Bajayo DE, Shatz D. Lumbar artery pseudoaneurysm: an unusual complication of penetrating abdominal trauma. Eur J Trauma. 2004;30:187-90.

12. Ratcliffe JF. The arterial anatomy of the adult human lumbar vertebral body: a microarteriographic study. J Anat. 1980;131:57-79.

Cite this article as: Aleixo C, Marinhas J, Santos F, Freitas R, Pereira RS. Life-threatening retroperitoneal hematoma after percutaneous vertebroplasty for lumbar fracture. Int J Res Orthop 2020;6:840-3. 